Filología y Lingüística 45 (2): 301-304 Octubre 2019 - Marzo 2020

ISSN: 0377-628X / EISSN: 2215-2628

Doi: https://doi.org/10.15517/rfl.v45i2.39249

URL: https://revistas.ucr.ac.cr/index.php/filyling

\title{
Emmanuel Marigno, Carlos Mata Induráin y Marie-Hélène Maux (editores). Cervantès quatre siècles après: Nouveaux objets, nouvelles approches. Binges: Éditions Orbis Tertius, 2017, 284 páginas
}

En una rápida "Presentación" (7-8), los editores indican la procedencia de estos trabajos reunidos en el volumen en ese orden de efemérides, de congresos y coloquios, que pobló el mundo académico durante el año 2015. Apenas nombran los trabajos; hubiera sido de gran interés explicarlos e introducirlos con arreglo al sugestivo título del libro. Ahora bien, los reúnen y ordenan en varias secciones. La primera, "Approches théoriques" (9- 52), comienza con el artículo de José Manuel Losada, "El 'mito' de don Quijote (2a. Parte): ¿con o sin comillas? En busca de criterios pertinentes del mito" (11-32). El autor vuelve sobre la noción de mito distinguiendo las diferencias entre un esquema narrativo, textual o de pensamiento; él lo define en tanto discurso con referente dentro de unas condiciones de aceptabilidad pragmática, cuyo referente sobrenatural sirve de encuadre al accionar del personaje; su desarrollo en esquemas narrativos de iniciación / superación son propios de esta interferencia entre el mundo natural y sobrenatural, que Losada observa como motor del mito pero que no convence al aplicarlo a Cervantes, por su premura en explicar un episodio como la Cueva de Montesinos (28), mucho menos a la renuncia de Alonso Quijano antes de morir al mundo de la caballería (29). Por su parte, Ángel Pérez Martínez, en "Variantes éticas cervantinas. Notas desde la antropología de don Quijote" (33-52), se preocupa por aproximarse a la noción de ser humano en la obra cervantina, a partir de esa locura que distorsiona tanto el pensamiento del caballero andante, así como "la propia identidad" a la hora de ver sus cualidades interiores, que Pérez Martínez luego traslada y complementa con valores y virtudes que posiciona el caballero en tanto comentario ético en el "Discurso de las armas y las letras", o en el capítulo 50 de la Primera Parte (51).

La sección, "Relectures linguistiques, poétiques et réécritures romanesques" (53-192), contempla siete trabajos escritos en francés y en español (¿y la unidad lingüística del libro?). En "Oudin, Franciosini et les premières traductions du Quichotte de 1605" (55-71), MarieHélène Maux se interesa por las traducciones al francés y al italiano del primer Quijote, respectivamente L’ingénieux don Quichotte de la Manche (César Oudin, 1614) y L'ingegnoso cittadino don Quisciotte della Mancia (Lorenzo Franciosini, 1622). Se impone un estudio comparativo de las traducciones con el fin de examinar su metodología de traducción; con esta finalidad se centra en el Cap. 25 de 1605 dentro del episodio de Sierra Morena y concluye que la traducción italiana es superior a la francesa (63), no solo por evitar el calco idiomático que haría incomprensible las palabras en la segunda lengua, sino también por su conocimiento de frases hechas y refranes del español. Sara Santa A. nos propone un estudio paratextual en "De Urganda al cachidiablo: la poesía en los preliminares y epilogales del Quijote" (73-93). Retoma la noción del afuera del libro en donde ubica a los "poemas preliminares" en tanto poemas laudatorios de tipo paródico-burlesco. Su intencionalidad jocosa Santa la contextualiza dentro de un efecto de ambigüedad y de inestabilidad (79) que hace imposible "el supuesto propósito 
de enaltecer la obra y rodearla de prestigio" (79), porque ni los registros ni el plano lingüístico en el que se ubican otorgan la congruencia textual requerida. Excelente trabajo que muestra también una solidez interpretativa, al tiempo que pone su atención además en el género de los epitafios de los poemas epilogales, cuya función sigue siendo también "desestabilizar la estructura de la obra" (85), con unos poemas risibles de tono elegiaco.

Por otro lado, el peso de los trabajos de esta sección se ubica en el dominio de la reescritura y de la impronta cervantina en la literatura española contemporánea. En "La impregnación quijotesca en Las crónicas mestizas (1992) de José María Merino" (95-110), Natalie Noyaret analiza la trilogía de novelas de aventuras consagradas al Nuevo Mundo, que Merino reúne bajo el título citado; su protagonista de nombre Miguel Villacé Yólotl, joven y mestizo, realza su capacidad de ensimismamiento y de ensoñación dentro de esa ambigüedad narrativa que suscita la vigilia / el sueño (100), permitiendo el establecimiento de esos juegos cervantinos entre la realidad y la ficción. El título del siguiente trabajo, muy largo por cierto aunque justificable en la tradición caballeresca, "Del caballero de la Triste Figura al caballero dormido: o cómo Gustavo Marín Garzo vuelve a dar vida al héroe cervantino", Caroline Bouhacein se interesa por la novela juvenil Dulcinea y el caballero dormido (2005). Dentro de esa reivindicación de la libertad imaginativa, la continuación del texto cervantino se establece en la figura de una Dulcinea, anciana y de carne y hueso, cuya "memoria borrosa" (115) insiste en el recuerdo y la memoria del caballero. Bouhacein comenta cómo en este tipo de recreaciones el hipotexto se acentúa (ese es el sentido de la parodia) y el texto cervantino no se borra para que coexista y dialogue con el nuevo. Se trata de esa tradición de adiciones y de olvidos en el que el palimpsesto logra su máxima efectividad intertextual. El trabajo de Gregoria Palomar, "Al morir don Quijote et le final de Sancho Panza d'Andrés Trapiello: un jeu cervantin sur l'auto-conscience des personnages" (129-149), ubica la perspectiva y el tema de su interés centrándose en el mito cosmogónico de la creación, del que tanto fantasmean los escritores y los artistas. Trapiello se decanta por ese punto final que suscita el final del personaje en Al morir don Quijote (2004) y El final de Sancho Panza y otras suertes (2014), cuando sendos textos de ficción, en tanto continuaciones y adiciones, plantean las condiciones del mito cervantino frente a los avatares de la memoria y la potencialidad de que sean otros personajes los que narren y "encanten" con su acto de palabra, o que las adiciones desaten nuevas prolongaciones de la historia, cuando se traslada a Sancho Panza con la sobrina de don Quijote a la Audiencia de Panamá. Se trata de un artículo bien planteado y argumentado el que ofrece Palomar, para que se complemente con el de Santiago López Navia, "Cide Hamete Benengeli y la conciencia de la historia en El final de Sancho Panza y otras suertes de Andrés Trapiello (2014)" (151-176). López Navia denomina esta novela de Trapiello como una "recreación" (156) y resalta no solo la evocación metaficcional de la "historia impresa", sino también el juego de "alusiones a sucesos, episodios y aventuras referidos en la novela original" (157), con el objetivo de proponernos tanto la continuidad como la coherencia diegética y narrativa, lo cual hablaría de la conciencia del escritor Trapiello y el manejo de los entresijos de la historia a la manera de su predecesor Cide Hamete. Con ello, se aborda ese embrague narrativo que es el escritor arábigo para que Trapiello configure la "pretendida unidad con [sus] continuaciones" (164) y el perspectivismo cervantino siga funcionando a la perfección, al confrontarse esa obsesión de los escritores posteriores a Cervantes, a saber: explorar las condiciones de una continuación al texto. Para terminar esta sección, Naima 
Lamari en "Tras las huellas de Cervantes en Misterioso asesinato en casa de Cervantes de Juan Eslava Galán” (177-192) plantea cómo Eslava Galán escribe una novela negra y la sitúa en los tiempos de la decadencia áurea; Eslava Galán la publica en 2015 y traspone un hecho de la biografía cervantina para hacer de la muerte de Gaspar de Espeleta un caso policiaco en el que se fustiga a Cervantes, su linaje y su biografía literaria, mientras el narrador policiaco retoma las pistas de la investigación y bifurca sus posibilidades textuales con alteraciones, amplificaciones, distorsiones (181), las cuales hablan mucho del claroscuro barroco y su sentido de la difuminación, no solo ambiental sino estructural. No puede pasar desapercibido este detalle: la investigación la lleva a cabo una detective, doña Dorotea, aficionada a la lectura y al Quijote mismo.

La última sección del libro, "Expérimentations intertextuelles et transmédiales" (193284), la conforman cuatro artículos, cuya orientación traduce ese interés por la transmedialidad y la readaptación semiótica. En "Intertextualité et mélange des genres dans Un certain Cervantès de Christian Lax" (195-218), Emmanuelle Souvignet focaliza su atención en una tira cómica francesa del año 2015, la cual a su vez tiene como motor el documental inglés Lost in La Mancha (2002) centrado sobre los avatares de la filmación de la película de Terry Gilliam (The Man Who Killed Don Quixote). Souvignet analiza los recursos de la intertextualidad cervantina a los que recurre Lax, al tiempo que la re-creación del personaje en la figura de Mike Cervantès, defensor de la biblioteca y del libro en nombre de la libertad, "passe aussi par la redéfinition onomastique des êtres et des choses" (204). El contexto de la obra es la mundialización y la postguerra, al presentar el personaje un cuadro de estrés postraumático que lo conduce a borrar las fronteras del tiempo y la realidad. También Morgane Kappès-Le Moing se interesa por otra tira cómica en "De Don Quijote à Batman: Le héros cervantin en Allemagne dans la bande dessinée de Flix" (219-239). Reconocida como noveno arte, la tira cómica recurre a las imágenes y a las palabras en esa configuración que resignifica una ilustración, al contar una historia y ponerla en movimiento. Flix, pseudónimo del autor alemán Félix Görman, lo hace con el directo título de Don Quijote (aparece primero por entregas y luego reunido en forma de libro en 2012), cuyo personaje es un viejo que habita un pueblo de nombre Tobosow y que pasa sus días protestando no solo contra la publicación de tiras cómicas en el periódico local, sino también contra la instalación de las eólicas en claro juego lúdico e intertextual. Las referencias son directas en su crítica a la modernidad, con lo cual también el personaje pierde la razón al tener la enfermedad de alzheimer (225). Al igual que Lax, Flix busca tanto la identificación con el héroe cervantino como la transposición de sus aventuras a un contexto contemporáneo, mientras las viñetas y los recursos visuales establecen diferentes niveles de la ficción (228). Por su parte, con otro título muy largo, “¿Juega don Quijote al fútbol americano? Apuntes sobre traducción y mediación en la adaptación cultural de Don Quixote para la televisión mexicana" (241-260), Carmela Mattza se interroga por la adaptación de un clásico y la mediación cultural (246), dentro de contextos de globalización y de cultura de masas, como puede ser la realizada por Roberto Gómez Bolaños en la serie televisiva Los caquitos (Televisa, 1987). Gómez Bolaños propone una condensación de los primeros diez capítulos de 1605 e introduce dentro de una escena onírica a un caballero extraño, vestido con accesorios deportivos del fútbol americano y que se codea con el Chómpiras y el Botijas, los dos rateros o "cacos" de la serie. Para Mattza, en ese mundo popular y marginal, a don Quijote se le reconoce para que introduzca en el imaginario popular mexicano un acercamiento a ese 
deporte extraño y foráneo al mundo mexicano en momentos en que se introducía a las masas (256). Y para terminar, Emmanuel Marigno se interesa en "Las Novelas ejemplares (1613) ilustradas por Antonio Zarco (1980): entre realismo y fantasía" (261-282) en las ilustraciones de Antonio Zarco a Rinconete y Cortadillo, las cuales se componen de doce linograbados policromados. Marigno subraya que, a diferencia de ilustradores que le han precedido, Zarco actualiza y renueva la representación iconográfica de esta novela ejemplar (267); al final de su artículo apenas esboza una tipología de las ilustraciones con arreglo a la mostración narrativa (extra o intradiegética, focalización externa o interna). Es una lástima que no se profundizara en ello, porque es necesario plantearse instrumentos de análisis a la hora de abordar no solo las ilustraciones y grabados que acompañan el libro, tal y como lo realiza Marigno, y que sirven en primer lugar de "ayuda-memoria" gráfica. Por último, este libro tiene la virtud de insistir en los fenómenos de transmedialidad que hoy circula en el mundo global recreando y reafirmando el "giro" quijotesco en la cultura mundial.

Jorge Chen Sham

Universidad de Costa Rica

Academia Nicaragüense de la Lengua Academia Norteamericana de la Lengua Española 